\title{
CO oxidation over monolayer manganese oxide films on $\mathrm{Pt}(111)$
}

\author{
Y. Martynova ${ }^{1}$, M. Soldemo ${ }^{2}$, J. Weissenrieder ${ }^{2}$, S. Sachert, ${ }^{3}$ S. Polzin, ${ }^{3}$ W. Widdra, ${ }^{3,4}$ S. \\ Shaikhutdinov ${ }^{1, *}$, H.-J. Freund ${ }^{1}$
}

\author{
${ }^{1}$ Abteilung Chemische Physik, Fritz-Haber-Institut der Max-Planck-Gesellschaft, 14195 Berlin, \\ Germany \\ ${ }^{2}$ Material Physics, KTH Royal Institute of Technology, 16440 Kista, Sweden \\ ${ }^{3}$ Institute of Physics, Martin-Luther-Universität Halle-Wittenberg, 06120 Halle, Germany \\ ${ }^{4}$ Max-Planck-Institut für Mikrostrukturphysik, 06120 Halle, Germany
}

\begin{abstract}
Ultrathin manganese oxide films grown on $\mathrm{Pt}(111)$ were examined in the low temperature $\mathrm{CO}$ oxidation reaction at near atmospheric pressures. Structural characterization was performed by x-ray photoelectron spectroscopy, Auger electron spectroscopy, highresolution electron energy loss spectroscopy, and temperature programmed desorption. The results show that the reactivity of $\mathrm{MnO}_{\mathrm{x}}$ ultrathin films is governed by a weakly bonded oxygen species, which may even be formed at low oxygen pressures ( $10^{-6} \mathrm{mbar}$ ). For stable catalytic performance at realistic conditions the films required highly oxidizing conditions $\left(\mathrm{CO}: \mathrm{O}_{2}<1: 10\right)$, otherwise the films dewetted, ultimately resulting in the catalyst deactivation. Comparison with other thin films on $\mathrm{Pt}(111)$ shows, that the desorption temperature of weakly bonded oxygen species can be used as a benchmark for its activity in this reaction.
\end{abstract}

Keywords: ultrathin oxide films; manganese oxide; CO oxidation. 


\section{Introduction}

Ultrathin oxide films, either formed on metal surfaces in oxygen atmosphere or grown on another metal substrate, have recently drawn attention as interesting catalytic materials for the oxidation reactions, particularly in CO oxidation at low temperatures [1-8]. The experimental results showed that the active surface under net oxidizing reaction conditions is often represented by an O-M-O trilayer ( $M=F e, I r, R u, R h, P d)$ that reveals much higher activity than the metal surface [9-13]. It has also been noted that the reaction had to be performed in excess of oxygen in the gas phase to maintain the active structure of the film, which otherwise dewets and/or becomes partially reduced. In the case of FeO(111) film on Pt(111), dewetting was shown to result in the catalysts deactivation [7]. At a variance, for $\mathrm{ZnO}(0001)$ partially covered $\mathrm{Pt}(111)$ films the interface showed a much higher reaction rate than observed for the closed films [14].

In the continuation of these studies, we addressed here the reactivity of manganese oxide films on Pt(111). Mn neighbors Fe in the Periodic Table, and therefore it would be interesting to compare the reactivities of these two metals oxides on the same support. Preparation of $\mathrm{MnO}_{\mathrm{x}}$ thin films on $\mathrm{Pt}(111)$ has recently been developed [15-17]. It is wellestablished now that the thinnest well-ordered $\mathrm{MnO}$ film, prepared by physical vapor deposition, grows as a non-polar, [001]-oriented MnO monolayer exhibiting an uniaxial reconstruction, ultimately resulting in a complex $(19 \times 1)$ superstructure [15]. Based on highresolution electron energy loss spectroscopy (HREELS) study, the thicker films showed a complex behavior, depending on the preparation conditions [16]. The films of ca. $1.3 \mathrm{~nm}$ in thickness, grown by chemical vapor deposition, exposed a $\mathrm{MnO}(111)$ surface as shown by low-energy electron diffraction (LEED) [17]. Based on angle scanned X-ray photoelectron diffraction study, it was proposed that this film is terminated by a O-Mn-O trilayer structure, i.e. the same structural motif as observed for the $\mathrm{FeO}(111)$ monolayer films at elevated oxygen pressures [10].

Manganese oxides naturally crystallize in $\mathrm{MnO}, \mathrm{Mn}_{3} \mathrm{O}_{4}, \mathrm{Mn}_{2} \mathrm{O}_{3}$ and $\mathrm{MnO}_{2}$ phases, with some like birnessite being non-stoichiometric. Catalytic properties of $\mathrm{MnO}_{\mathrm{x}}$ in oxidation reactions are commonly discussed in terms of multi-valency of $\mathrm{Mn}$ that facilitates supplying lattice oxygen to reactive ad-species. Aimed at a fundamental understanding of the 
reactivity of $\mathrm{MnO}_{x}$ surfaces many publications focused on the epitaxial growth and structural properties of $\mathrm{MnO}_{\mathrm{x}}$ thin films. Besides the already mentioned film growth on Pt(111), well-ordered films could be grown on $\mathrm{Ag}(001)[18], \mathrm{Pd}(100)[19]$, and $\mathrm{Rh}(100)[20]$, to name a few. Very recently, a monolayer film with O-Mn-O structure was reported for $\operatorname{Rh}(111)[21]$.

In this work, we address the structure and reactivity of ultrathin $\mathrm{MnO}_{\mathrm{x}}$ films in $\mathrm{CO}$ oxidation. Ex situ structural characterization of the films by LEED, HREELS, Auger electron spectroscopy (AES), and temperature programmed desorption (TPD), was complemented by in situ high-pressure x-ray photoelectron spectroscopy (HP-XPS) with synchrotron radiation.

\section{Experimental}

The experiments were performed in three different UHV chambers. The first chamber (at FHI, Berlin) is equipped with LEED optics combined with AES for sample characterization and a differentially-pumped quadrupole mass spectrometer (QMS) for TPD studies. The chamber houses a small $(30 \mathrm{ml})$ gold-plated HP cell connected to a gas chromatograph (GC) for the reactivity measurements as described elsewhere [7]. A doubleside polished Pt(111) single crystal was spot welded to the two Ta wires used for resistive heating and also for cooling by filling a manipulator rod with liquid nitrogen. The temperature was measured by a type $K$ thermocouple spot-welded to the edge of the crystal. The HP cell is sealed via a Viton O-ring and then filled with $\mathrm{CO}$ and $\mathrm{O}_{2}$ in the mbar pressure range (He balance to 1 bar) at $300 \mathrm{~K}$. Gas intermixing is achieved with a circulating membrane pump.

The similarly prepared oxide films on Pt(111) were studied at the synchrotron radiation facility MAX-lab (beamline 1511-1), Lund University, Sweden. The preparation UHV chamber of the endstation[22] was equipped with LEED. A load-lock was used for sample transfer without breaking vacuum. The main chamber houses a hemispherical analyzer for XPS and a HP cell that allows catalytic reactivity measurements at pressures up to several mbar. The monochromated synchrotron radiation enters the cell via a $\mathrm{Si}_{3} \mathrm{~N}_{4}$ membrane 
window while the electrons escape to the analyzer through an aperture ( $1 \mathrm{~mm}$ in diameter) placed a few millimeters away from the crystal surface. The crystal is heated in the preparation chamber by direct electron bombardment of the sample plate. In the HP cell, the heating is provided through electron bombardment of the reactor wall. The sample temperature is measured both by a type $\mathrm{K}$ thermocouple and a pyrometer. The reaction was carried in a flow regime and monitored by QMS.

The third chamber (at MLU Halle-Wittenberg) is equipped with a HREELspectrometer (Delta 05, from Specs), LEED, and TPD facilities. If not stated otherwise the HREEL-spectra were recorded at a sample temperature of $85 \mathrm{~K}$ using electron kinetic energies of $4 \mathrm{eV}$ in specular conditions with a total scattering angle of $120^{\circ}$. TPD spectra were measured with QMS using Feulner cup [23].

In all three chambers, clean metallic Pt(111) surfaces were prepared by cycles of $\mathrm{Ar}^{+}$ ion sputtering and annealing in UHV or $\mathrm{O}_{2}$ ambient. The manganese oxide films were prepared by $\mathrm{Mn}$ vapor deposition using electron beam assisted evaporators in $\mathrm{O}_{2}$ ambient $\left(<10^{-7} \mathrm{mbar}\right)$. The film coverage was determined by CO titration of the Pt surface using TPD.

\section{Results and discussion}

\subsection{Preparation and structural characterization}

The deposition of $\mathrm{Mn}$ atoms on a $\mathrm{Pt}(111)$ surface at $375 \mathrm{~K}$ in $5 \times 10^{-8}$ mbar $\mathrm{O}_{2}$ leads to the formation of a $\mathrm{MnO}(100)-(19 \times 1)$ film. Its long-range order is further improved by UHV annealing at 600 - $750 \mathrm{~K}$ as judged by LEED. The film is characterized by a sharp FuchsKliewer phonon at $365 \mathrm{~cm}^{-1}$, shown in Fig. 1a for a coverage of $\sim 0.3$ monolayers (ML) as measured by CO TPD. This phonon mode is attributed to the collective vertical vibration of the oxygen sub-lattice against the Mn sub-lattice.[15] Subsequent annealing to $750 \mathrm{~K}$ in $10^{-6}$ mbar $\mathrm{O}_{2}$ for 15 min converts the film into a new, so-called "oxygen-rich" structure that shows no longer the phonon at $365 \mathrm{~cm}^{-1}$, but new features at 478, 583 and $721 \mathrm{~cm}^{-1}$ (Fig. 1b). The energy loss at $478 \mathrm{~cm}^{-1}$ can be straightforwardly assigned to the frustrated translation of atomic oxygen present on the uncovered $\mathrm{Pt}(111)$ surface due to the sample 
cooling in the oxygen atmosphere. This peak diminishes at increasing film coverage, and can be removed by heating to $700 \mathrm{~K}$ in UHV without changing the manganese oxide related vibrations. However, upon heating to the temperatures above $1050 \mathrm{~K}$, the film is fully transformed back to a well-ordered $(19 \times 1)$ structure as judged by LEED and HREELS.

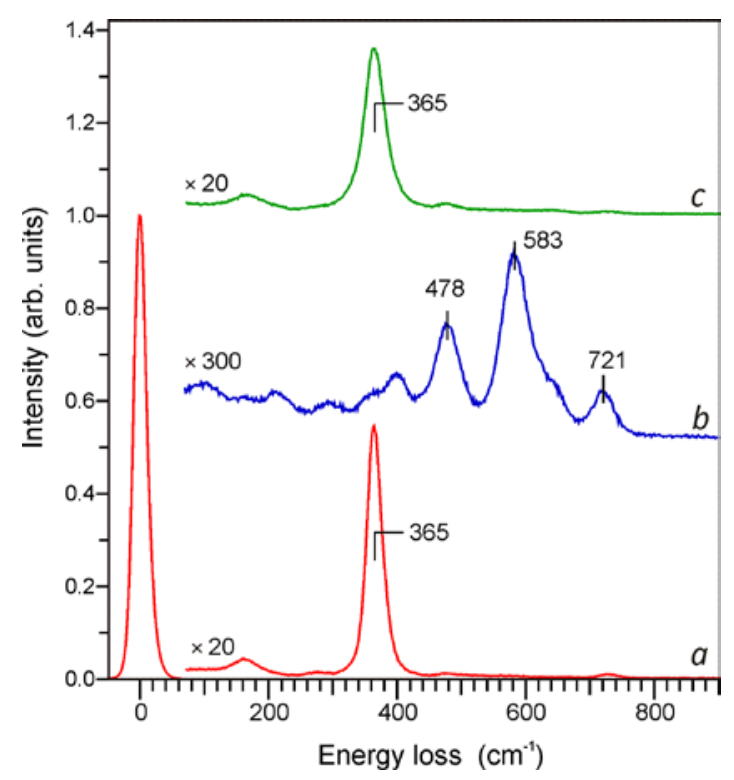

Figure 1. HREEL spectra of a $0.3 \mathrm{ML} \mathrm{MnO}$ ultrathin film on Pt(111) grown at $375 \mathrm{~K}$ in $5 \times 10^{-8} \mathrm{mbar}_{2}$ (a) and after oxidation at $750 \mathrm{~K}$ in $10^{-6} \mathrm{mbar}_{2}$ for $15 \mathrm{~min}$ (b). Spectrum (c) shows the film (b) after six cycles of $\mathrm{CO}$ adsorption ( $200 \mathrm{~L}$ at $85 \mathrm{~K}$ ) and subsequent annealing to $585 \mathrm{~K}$.

The vibrational spectra of the O-rich film are shown in more details in Fig. 2 for 0.8 ML films prepared either in an ${ }^{16} \mathrm{O}_{2}$ or an ${ }^{18} \mathrm{O}_{2}$ atmosphere. The films show the characteristic phonon modes at 583 and $721 \mathrm{~cm}^{-1}$ in the ${ }^{16} \mathrm{O}$ containing film, which red-shift by 16 and 37 $\mathrm{cm}^{-1}$, respectively, for the ${ }^{18} \mathrm{O}$ containing oxide film. The weaker low frequency modes around 360 and $400 \mathrm{~cm}^{-1}$ also show a notable isotopic shift upon ${ }^{16} \mathrm{O} /{ }^{18} \mathrm{O}$ substitution. We assign, therefore, the modes at 583 and $721 \mathrm{~cm}^{-1}$ to the dipole-active Fuchs-Kliewer phonon-polaritons, whereas the low frequency modes are assigned to microscopic phonon modes as discussed in the details for the case of $\mathrm{NiO}(100)$ thin films on $\mathrm{Ag}(100)$ [24]. 


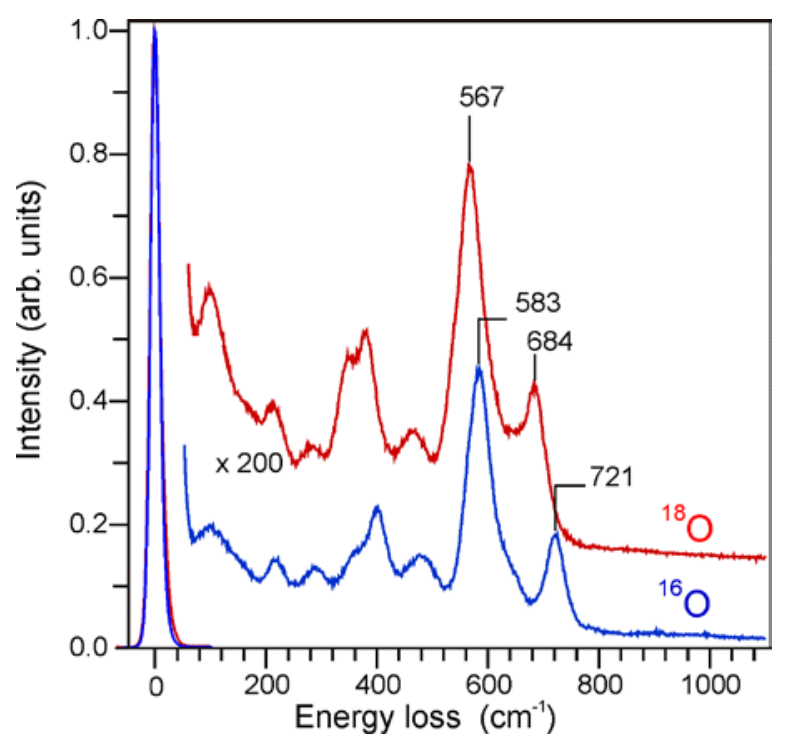

Figure 2. HREEL spectra of "oxygen-rich" $\mathrm{MnO}_{x}$ films prepared with ${ }^{16} \mathrm{O}_{2}$ (bottom) and ${ }^{18} \mathrm{O}_{2}$ (top), respectively. The film coverage is $0.8 \mathrm{ML}$.

The oxygen desorption states in the O-rich $\mathrm{MnO}_{x}$ films were studied by TPD (see Fig. 3a). For $\mathrm{MnO}(100)-(19 \times 1)$ oxygen desorption takes place in a single peak at $1175 \mathrm{~K}$, whereas the O-rich $\mathrm{MnO}_{x}$ film exhibits three additional peaks between 850 and $1100 \mathrm{~K}$. The amount of oxygen released during thermal decomposition was calibrated vs a well-known $\mathrm{O}(2 \times 2)$ $\mathrm{Pt}$ (111) surface possessing an 0.25 ML of oxygen. This measured stoichiometry of the O-rich $\mathrm{MnO}_{\mathrm{x}}$ film was around $\mathrm{Mn}: \mathrm{O}=0.4( \pm 0.15)$, that is close to a $\mathrm{MnO}_{2}$ compositional stoichiometry.

The film reconstruction into the O-rich phase is also accompanied by changes in LEED, which are most visible for the films at high coverage as depicted in Fig. 3b, where six inequivalent spots surround the hexagonal $\mathrm{Pt}(111)-(1 \times 1)$ spots. Such a Moire-like pattern is indicative for a hexagonal (111)-oriented film with a $7 \%$ lattice mismatch with respect to the $\mathrm{Pt}(111)$ substrate. Taken all these findings together, we have tentatively proposed that the O-rich film consists of a hexagonal O-Mn-O trilayer adsorbed on Pt(111), i.e. similar to the previously found structure of $\mathrm{FeO}_{2-\mathrm{x}}$ films [10]. 

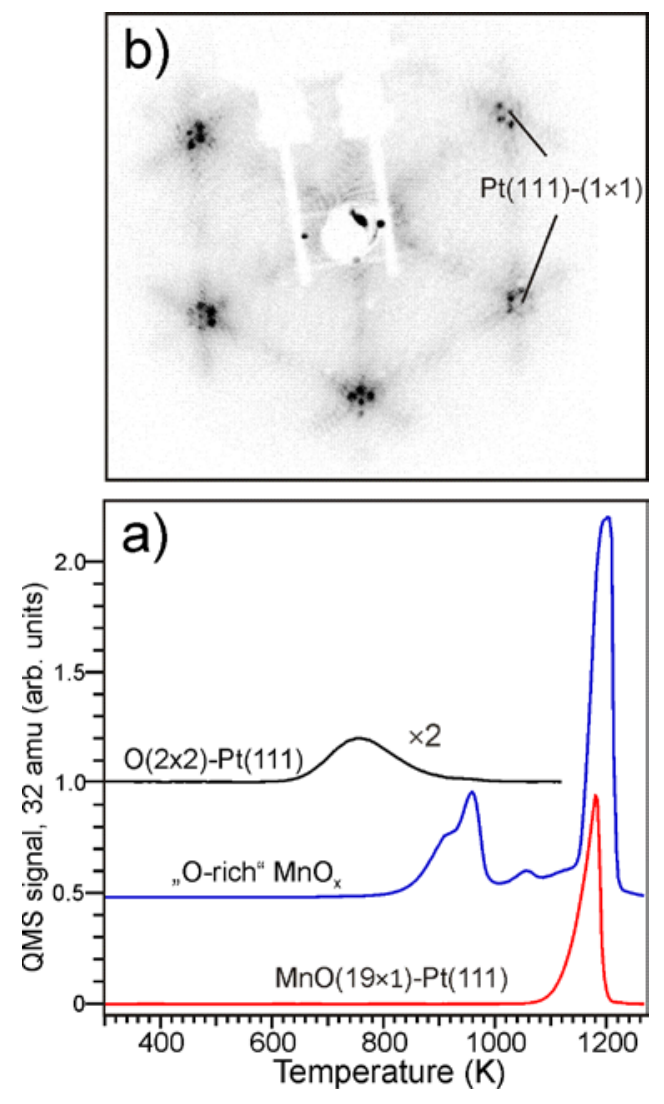

Figure 3. (a) Oxygen (32 amu) desorption traces of the $\mathrm{MnO}(100)-(19 \times 1)$ film (bottom, red), the "Orich" $\mathrm{MnO}_{x}$ film on $\mathrm{Pt}(111)$ (middle, blue), and the $\mathrm{O}(2 \times 2)-\mathrm{Pt}(111)$ phase (top, black). The heating rate is $5 \mathrm{~K} \mathrm{~s}^{-1}$ for all spectra. (b) LEED pattern of the "O-rich" $\mathrm{MnO}_{\mathrm{x}}$ film prepared by oxidation of a $\mathrm{MnO}(100)-(19 \times 1)$ film at $750 \mathrm{~K}$ in $10^{-6} \mathrm{mbar}_{2}$ for $15 \mathrm{~min}$ (coverage $0.9 \mathrm{ML}$, electron energy $100 \mathrm{eV}$ ).

In contrast to the $\mathrm{MnO}(19 \times 1)$ films, the O-rich films readily react with $\mathrm{CO}$. To illustrate this, Figure 1c shows the HREEL- spectrum of the O-rich film after cycles of $200 \mathrm{~L}$ $\mathrm{CO}$ adsorption at $85 \mathrm{~K}$ and heating to $585 \mathrm{~K}$. It is clear that the O-rich film is fully reduced to the $(19 \times 1)$ structure as identified by the reappearance of the characteristic $365 \mathrm{~cm}^{-1}$ and the disappearance of 583 and $721 \mathrm{~cm}^{-1}$ phonon bands.

\subsection{CO oxidation at nearly atmospheric pressures.}

\subsubsection{Structural characterization}

For reactivity studies, the $\mathrm{MnO}(19 \times 1)-\mathrm{Pt}(111)$ monolayer films were prepared by a $\mathrm{Mn}$ deposition at $300 \mathrm{~K}$ in UHV and subsequent annealing in $10^{-6} \mathrm{mbar} \mathrm{O}_{2}$ at $700 \mathrm{~K}$, which resulted in a LEED pattern displayed in Fig. 4a. This pattern results from superposition of 
three rotational domains each showing a $(2.37 \times 1)$ periodicity.[15] The same or newly deposited films oxidized at higher temperatures, $\sim 850 \mathrm{~K}$ in this case, showed a much more complex LEED pattern (Fig. 4b). Yet structurally unidentified such films showed oxygen enrichment, resulting in a $\mathrm{MnO}_{x}(x=1.2-1.4)$ composition measured by AES using the $\mathrm{MnO}$ $(19 \times 1)$ structure for calibration.
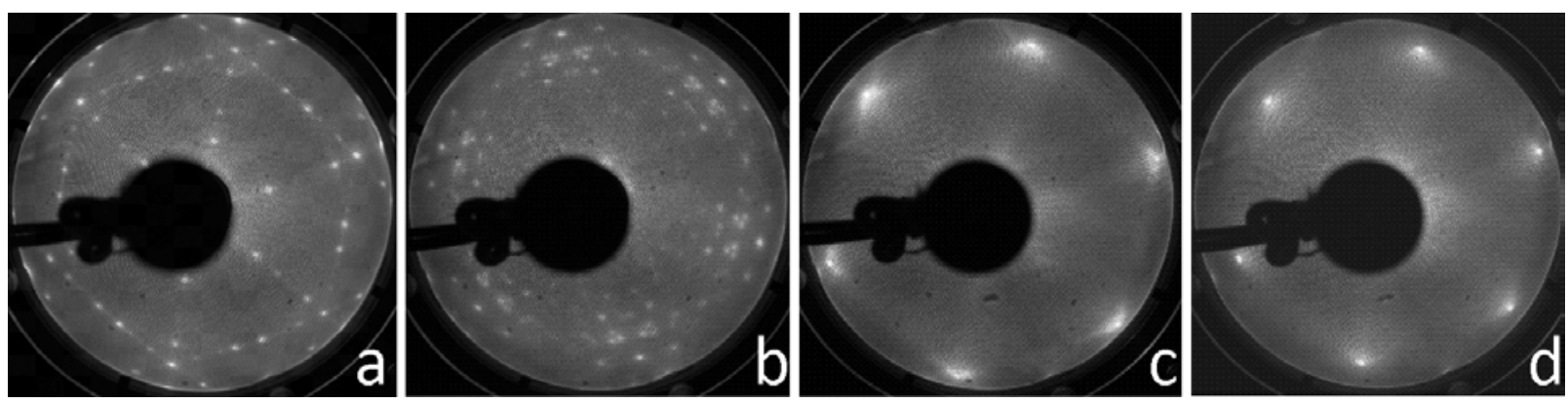

Figure 4. LEED patterns (at $70 \mathrm{eV}$ ) of monolayer manganese oxide films grown on $\mathrm{Pt}(111)$ : $\mathrm{MnO}(19 \times 1)-\mathrm{Pt}(111)(\mathrm{a})$; a $\mathrm{MnO}_{x}$ phase formed by oxidation in $10^{-6} \mathrm{mbar}$ at $850 \mathrm{~K}$ (b); a film prepared by oxidation at $10^{-4} \mathrm{mbar}_{2}$ at $700 \mathrm{~K}(\mathrm{c})$. Shown in (d) are the films (a,b) exposed to $20 \mathrm{mbar}_{2}$ at $450 \mathrm{~K}$.

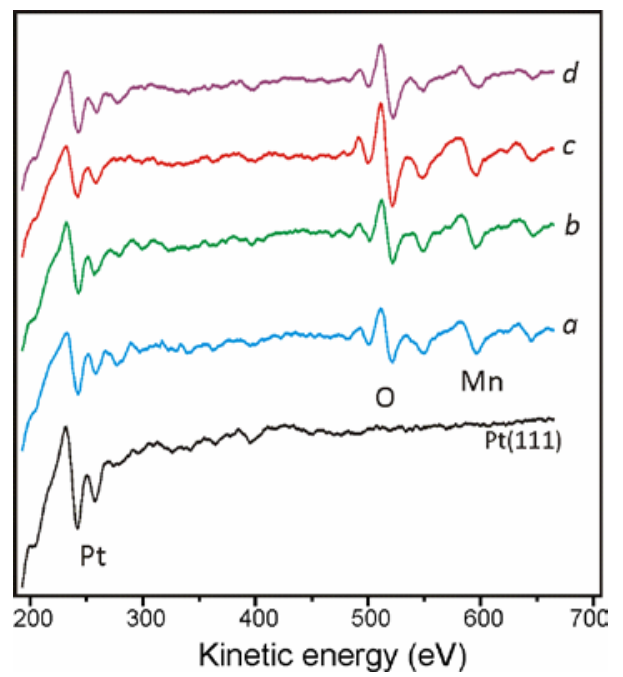

Figure 5. Auger spectra of the same films (a-d) presented by LEED in Fig. 4 (see the preparation conditions therein). The spectrum for clean Pt(111) is shown for comparison.

The monolayer films prepared by oxidation at much higher $\mathrm{O}_{2}$ pressures $\left(10^{-4} \mathrm{mbar}\right)$ at $700 \mathrm{~K}$ showed further enrichment in oxygen, as judged by AES (Fig. 5c), resulting in a close to $\mathrm{MnO}_{2}$ compositional stoichiometry. The respective LEED pattern (Fig. 4c) is similar to that shown in Fig. $3 a$ and as such it could be assigned to the O-Mn-O trilayer structure. 
Another candidate for such O-rich films would be the "stripe" structure which, according to density functional theory (DFT) calculations,[25] competes with the O-terminated unreconstructed bulk (111) face for the most stable structure at high chemical potentials of oxygen.

To examine structural transformations of the monolayer films under $\mathrm{CO}$ oxidation conditions at elevated pressures (further studied with GC in the HP reactor, see below), the "as prepared" films were exposed to $20 \mathrm{mbar}_{2}$ at $450 \mathrm{~K}$ for $10 \mathrm{~min}$. The resulting surfaces showed LEED very similar to those obtained on the "O-rich" films formed at $10^{-4} \mathrm{mbar}_{2}$. In addition, the Auger spectrum (Fig. 5d) revealed a close to $\mathrm{MnO}_{2}$ composition. It is noteworthy that the films did not dewet after HP treatments, as subsequent CO titration experiments did not reveal the Pt(111) surface.

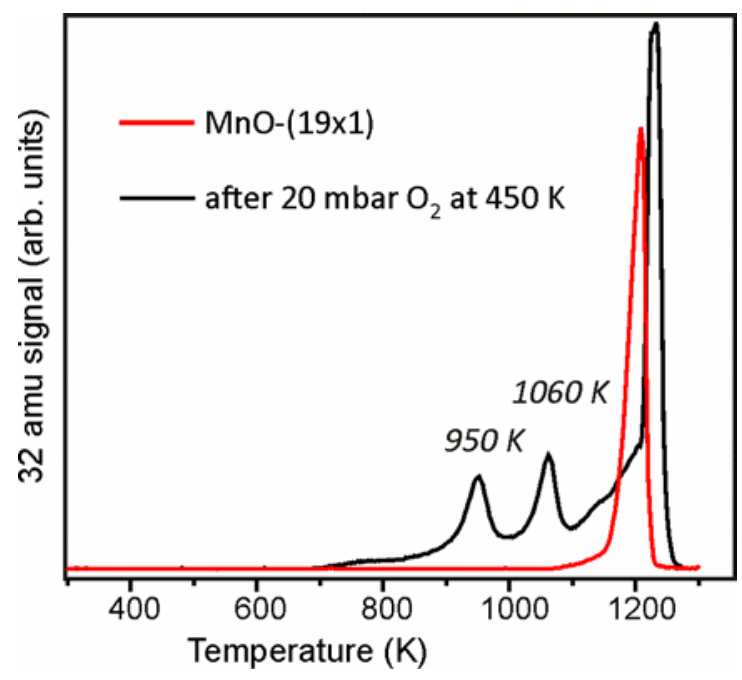

Figure 6. Oxygen desorption from the monolayer $\mathrm{MnO}_{\mathrm{x}}$ films on $\mathrm{Pt}(111)$ : "as prepared" in $10^{-6} \mathrm{mbar}$ $\mathrm{O}_{2}$ at $850 \mathrm{~K}$, and after exposure to $20 \mathrm{mbar}_{2}$ at $450 \mathrm{~K}$. The heating rate is $3 \mathrm{~K} \mathrm{~s}^{-1}$.

Oxygen enrichment at high $\mathrm{O}_{2}$ pressures is also observed in thermal desorption spectra. Figure 6 displays TPD profiles for 32 amu signal measured for the $\mathrm{MnO}(19 \times 1)$ $\mathrm{Pt}(111)$ film and the film further treated with $20 \mathrm{mbar}_{2}$ at $450 \mathrm{~K}$. The $\mathrm{MnO}-(19 \times 1)$ film showed only one peak at $1200 \mathrm{~K}$, thus indicating only one type of oxygen species in the film. In contrast, the $\mathrm{O}_{2}$-treated film showed additional well-resolved signals at 950 and $1060 \mathrm{~K}$ 
indicating its sequential transformation to the "O-poor" film that ultimately decomposes at $\sim 1230 \mathrm{~K}$. The observed spectral changes are very similar to those shown in Fig. 3a measured in a different setup for a differently prepared "O-rich" sample. The peak centered at $950 \mathrm{~K}$ might be associated with oxygen atoms in the topmost layer of the O-Mn-O trilayer, like observed for a well-ordered O-Fe-O film on Pt(111) [10]. The peak at $1060 \mathrm{~K}$, which obviously gains intensity for the sample prepared under high pressure conditions (compare to Fig. 3a), could be assigned either to another O-rich structure, coexisting with the aboveproposed O-Mn-O structure, or to an intermediate structure formed upon heating during TPD. In principle, the former scenario would be in agreement with the DFT calculations predicting several stable structures for the $\mathrm{MnO}(111)$ surface at high chemical potential of oxygen [25]. Therefore, the oxidation conditions may affect the distribution of oxygen species in those films. Indeed, the peak centered at $\sim 960 \mathrm{~K}$ in Fig. 3a exhibits a shoulder which is missing in Fig. 6. However, regardless of the nature of these peaks, close similarity between TPD profiles of the films treated at low $\left(10^{-6} \mathrm{mbar}\right)$ and high $(20 \mathrm{mbar})$ pressures is quite remarkable. This finding suggests that the resultant structure is stable in a wide range of oxygen chemical potentials, although the films formed in the HP cell are poorly ordered as compared to the films prepared at low pressures and higher temperatures (compare Fig. $3 b$ and $4 d)$.

\subsubsection{Reactivity and post-characterization}

The CO oxidation reaction was first examined under the same conditions as previously used for other oxide films studied in the group, $[7,14,26]$ i.e. in the mixture of 10 mbar $\mathrm{CO}$ and 50 mbar $\mathrm{O}_{2}$ balanced by He to 1 bar at $450 \mathrm{~K}$. Figure 7a shows kinetics of $\mathrm{CO}_{2}$ production over a monolayer $\mathrm{MnO}$ film as well as of monolayer $\mathrm{FeO}(111)$ film and bare $\mathrm{Pt}$ (111) surface studied with the same setup for comparison. Clearly, the reactivity of MnO is significantly lower than of the FeO film and just slightly higher than of Pt(111). After ca. 15 min, the reaction over $\mathrm{MnO}$ slows down and then stops, indicating the catalysts deactivation. 
Characterization of the post-reacted samples by LEED, AES and TPD revealed that the $\mathrm{MnO}_{\mathrm{x}}$ films underwent severe dewetting which was accompanied in addition by carbon deposition, i.e. very similar to the reaction over the FeO films under $\mathrm{O}_{2}$-lean conditions.[7] The spent $\mathrm{MnO}$ catalysts showed a well-known $\mathrm{Pt}(111)-\mathrm{c}(4 \times 2) \mathrm{CO}$ pattern, and a substantial CO uptake by Pt(111) as measured by TPD. Heating of the sample to $600 \mathrm{~K}$ in UHV led to partial re-wetting of the Pt surface by the MnO-(19×1) film (not shown here).
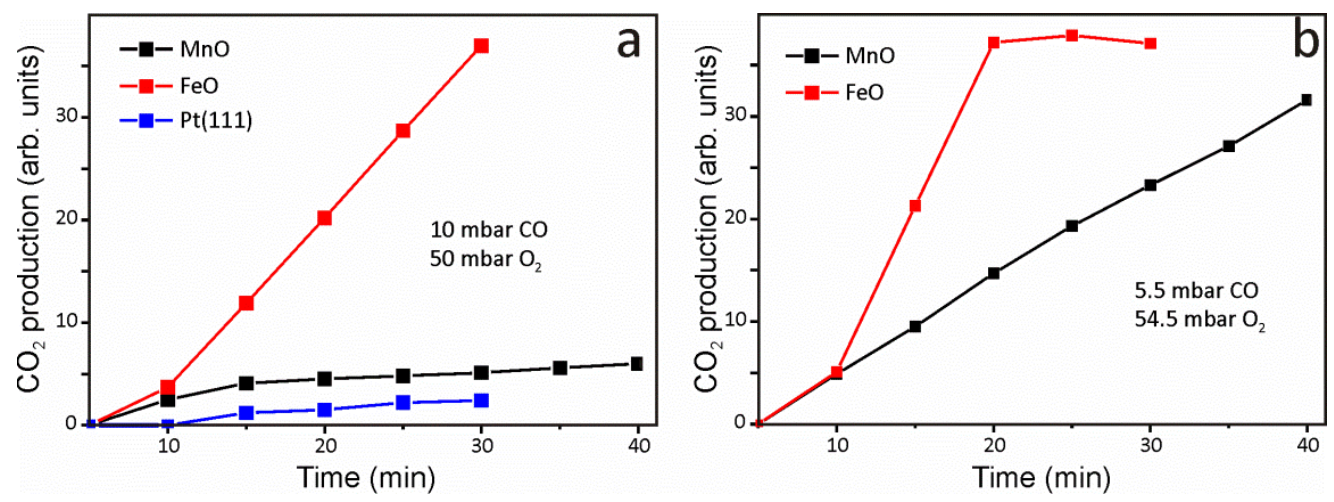

Figure 7. Integrated $\mathrm{CO}_{2}$ production over monolayer $\mathrm{MnO}_{x}$ film on $\mathrm{Pt}(111)$. Reaction conditions: 10 mbar CO, 50 mbar $_{2}, 450 \mathrm{~K}$ (a); 5.5 mbar CO, 54.5 mbar O$_{2}, 450 \mathrm{~K}$ (b); He balance to 1 bar. Data for $\mathrm{FeO}(111) / \mathrm{Pt}(111)$ and clean $\mathrm{Pt}(111)$, measured under the same conditions, are shown for comparison. Note that $\mathrm{CO}_{2}$ production for the $\mathrm{FeO}$ film in (b) saturates due to the $100 \% \mathrm{CO}$ conversion after $20 \mathrm{~min}$.

In order to prevent dewetting, the reaction was further carried out at $\mathrm{CO}: \mathrm{O}_{2}=1: 10$ while keeping the total reactant pressure of $60 \mathrm{mbar}$, i.e. $5.5 \mathrm{mbar} \mathrm{CO}$ and $54.5 \mathrm{mbar} \mathrm{O}_{2}$, balanced by He to 1 bar. Note, that post-characterization by AES and TPD confirmed that the $\mathrm{MnO}_{\mathrm{x}}$ film remains closed and showed all oxygen desorption features of the O-rich films shown in Fig. 6. Figure 7b clearly shows no deactivation and a much higher reactivity, although still lower than the $\mathrm{FeO}$ film. It is instructive to recall here that $\mathrm{FeO}(111)$ films on $\mathrm{Pt}(111)$ showed $\mathrm{O}_{2}$ desorption at temperatures as low as $840 \mathrm{~K}$ [10], whereas the most weakly bound oxygen on the $\mathrm{MnO}$ film desorbs at $950 \mathrm{~K}$, i.e. considerably higher. In this respect, it is noteworthy that closed $\mathrm{ZnO}$ films, which showed desorption at $1070 \mathrm{~K}$ [14], were found essentially inert under the same conditions. Therefore, the $\mathrm{O}_{2}$ desorption temperature, thus 
characterizing weakly bonded oxygen species in the film, can be used as a benchmark for activity in this reaction.

\subsubsection{High-pressure XPS study}

The monolayer films for in situ high pressure XPS studies were prepared by Mn deposition in $5 \times 10^{-8} \mathrm{mbar}_{2}$ at $300 \mathrm{~K}$ followed by oxidation in $10^{-6} \mathrm{mbar}_{2}$ at $850 \mathrm{~K}$. The "as prepared" films showed a LEED pattern virtually identical to that shown on Fig. 4b.

Exposure to $10^{-5} \mathrm{mbar}$ at $300 \mathrm{~K}$ gives rise to additional $\mathrm{O}$ species that appear at $530.8 \mathrm{eV}$ as a shoulder at the high binding energy (BE) side of the main peak centered at $529.2 \mathrm{eV}$ (Fig. 8). The shoulder gains intensity and shifts to $531.1 \mathrm{eV}$ after further treatment in 1.3 mbar of $\mathrm{O}_{2}$ at $450 \mathrm{~K}$ in the HP cell. The main peak only slightly shifts from $529.2 \mathrm{eV}$ to $529.4 \mathrm{eV}$ upon oxidation. Concomitantly, the BE of $\mathrm{Mn} 2 \mathrm{p}_{3 / 2}$ core level shifts from $640.7 \mathrm{eV}$ to $641.1 \mathrm{eV}$ (not shown), thus indicating a higher oxidation state of $\mathrm{Mn}$ in the O-rich films, on average. Note that the $\mathrm{Mn} 2 \mathrm{p}$ spectrum is rather complex (as in several $3 \mathrm{~d}$ transition metals) due to the multiplet splitting that renders quantitative analysis difficult [27].

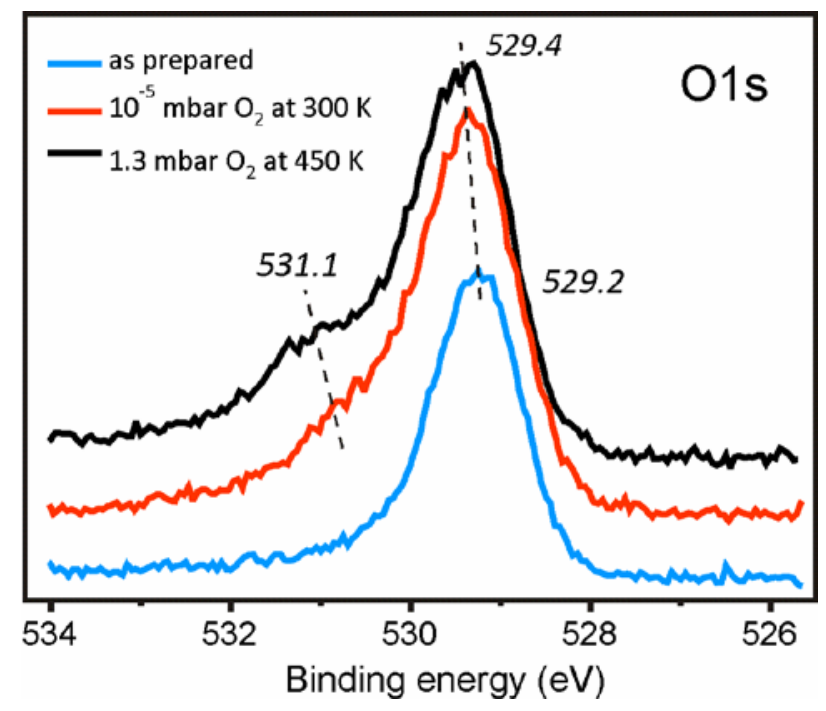

Figure 8. XP-spectra of the $\mathrm{O} 1 \mathrm{~s}$ region $\left(\mathrm{h}=750 \mathrm{eV}\right.$ ) of a monolayer $\mathrm{MnO}_{\mathrm{x}}$ film grown on $\mathrm{Pt}(111)$ : as prepared (blue), after exposure to $10^{-5} \mathrm{mbar}_{2}$ at $300 \mathrm{~K}$ (red), after exposure $1.3 \mathrm{mbar}_{2}$ at $450 \mathrm{~K}$ (black). The spectra are offset for clarity. 
Figure 9 displays the reaction kinetics monitored with QMS at stepwise increasing CO flow rate while keeping the $\mathrm{O}_{2}$ flow rate constant $(5 \mathrm{ml} / \mathrm{min})$. It is clear that the $\mathrm{CO}_{2}$ signal linearly responds to the changes in the CO concentration, thus suggesting a first order reaction for $\mathrm{CO}$. Note that in the similar experiment over clean $\mathrm{Pt}(111)$ almost no response in $\mathrm{CO}_{2}$ signal was observed. With increasing the $\mathrm{CO}: \mathrm{O}_{2}$ flow rates up to $\sim 1: 10$, the activity drops down dramatically, indicating that the surface is deactivated. This is in agreement with the results of Fig. 7 showing that the $\mathrm{CO}: \mathrm{O}_{2}$ ratio is critical for the steady state reactivity.

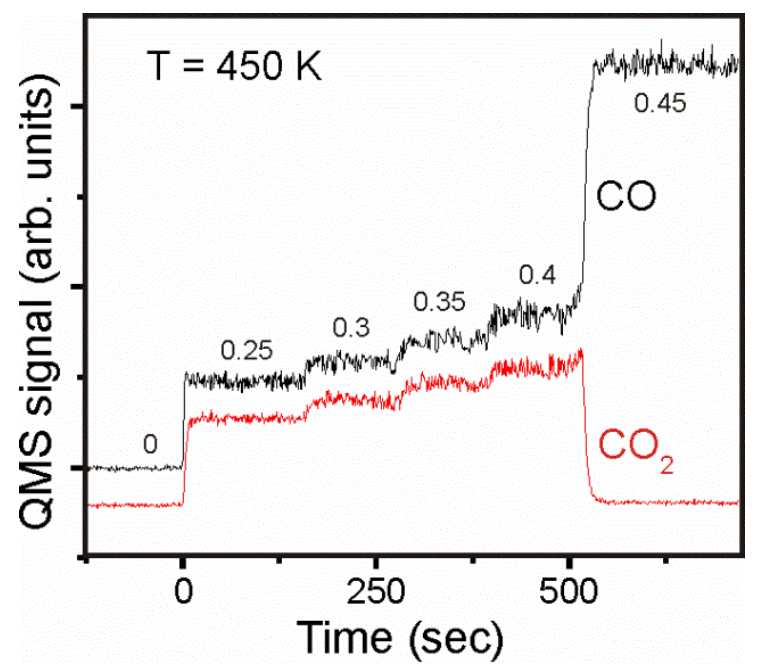

Figure 9. $\mathrm{CO}$ oxidation kinetics upon stepwise increasing of a $\mathrm{CO}$ flow rate over a monolayer $\mathrm{MnO}_{\mathrm{x}}$ film on $\mathrm{Pt}(111)$ at $450 \mathrm{~K}$ and constant $\mathrm{O}_{2}$ flow of $5 \mathrm{ml} / \mathrm{min}$. The $\mathrm{CO}$ flow rate (in $\mathrm{ml} / \mathrm{min}$ ) is indicated.

The catalyst deactivation is accompanied by the substantial changes in the $01 \mathrm{~s}$ states. Figure 10 shows in-situ XP spectra taken from the sample in active and deactivated states. The prominent shoulder to the main peak at $529.4 \mathrm{eV}$ present on the active surface disappears on the deactivated surface. It cannot be restored by pure $\mathrm{O}_{2}$ flow at the same $450 \mathrm{~K}$, and the film remains almost inactive in a new reaction run. The deactivated surface readily adsorbs CO seen in the C 1s region at 286-287 eV (see Fig. S1 in the Supporting Information) and at $\sim 532.7 \mathrm{eV}$ in $01 \mathrm{~s}$ region that has tentatively been assigned to CO on Pt. 
Also, the spent catalyst exhibited clearly visible changes in the $M n 2 p_{3 / 2}$ region (see Fig. S2). The two well-resolved peaks at 640.8 and $641.6 \mathrm{eV}$ indicate very different $\mathrm{Mn}$ coordination and, probably, oxidation states in the deactivated film. Taken together these results suggest that the film dewets under $\mathrm{O}_{2}$-lean conditions, thus forming $\mathrm{MnO}_{x}$ particles on $\mathrm{Pt}(111)$, in agreement with the results presented above in Section 3.2.2.

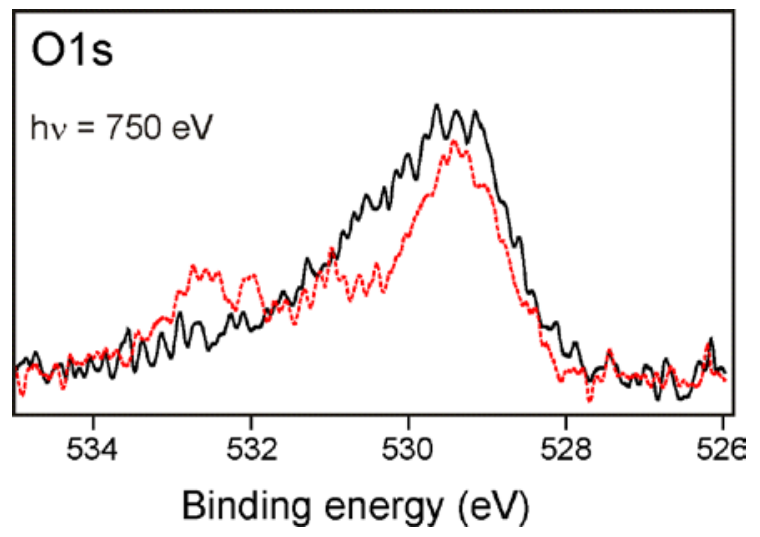

Figure 10. In situ XP spectra of the 01 s region in a $\mathrm{MnO}_{x} / \mathrm{Pt}(111)$ film measured under reaction conditions (450 K; $\mathrm{CO}: \mathrm{O}_{2}=1: 10$; total pressure $1.3 \mathrm{mbar}$ ) in the active (black solid line) and deactivated (red dashed line) states. The feature at $\sim 532.6$ is assigned to the adsorbed CO.

Figure 11 shows the kinetics of $\mathrm{CO}$ oxidation (a total pressure 1 mbar; a $\mathrm{CO}: \mathrm{O}_{2}$ flow ratio is $1: 10$ ) over the monolayer film at increasing reaction temperature following a steady state regime at $450 \mathrm{~K}$. It appears that after $500 \mathrm{~K}$ the film underwent deactivation as can be concluded from $\mathrm{CO}$ concentration increase and $\mathrm{CO}_{2}$ concentration decrease in the end of each temperature step. The remarkable gain of the reactivity at $530 \mathrm{~K}$ could be caused by morphological changes (dewetting), thus resulting in ill-defined $\mathrm{MnO}_{\mathrm{x}}$ particles on $\mathrm{Pt}(111)$, which then dominates the reactivity. Adsorbed $\mathrm{CO}$ can be removed from the deactivated surface by oxygen treatment, but the catalyst did not regain its initial activity when the experiment was re-started at $450 \mathrm{~K}$. 


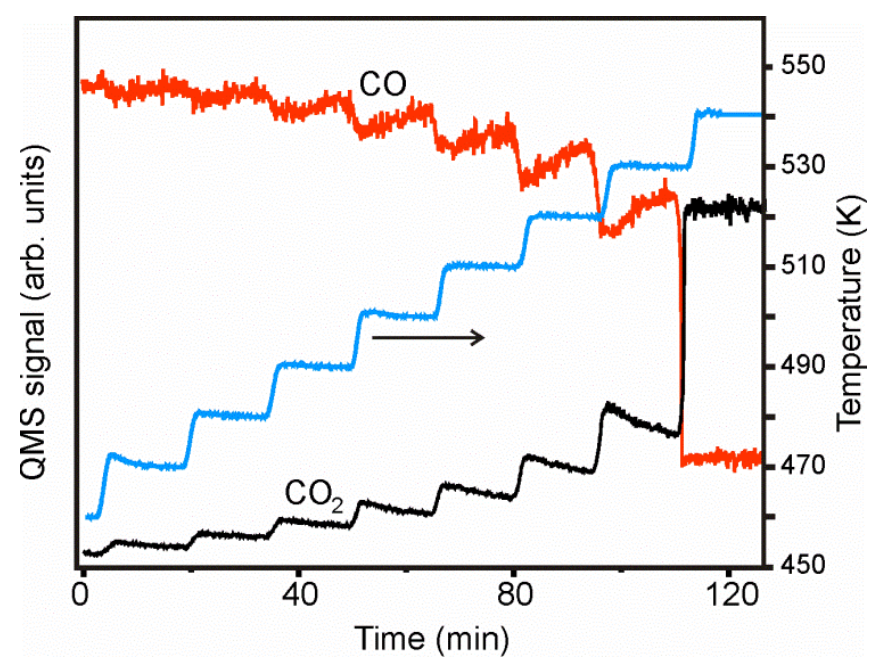

Figure 11. QMS signals of $\mathrm{CO}(28 \mathrm{amu})$ and $\mathrm{CO}_{2}(44 \mathrm{amu})$ in the flow reactor over a monolayer $\mathrm{MnO}_{\mathrm{x}}$ film. A flow rate ratio is $\mathrm{CO}: \mathrm{O}_{2}=1: 10$, a total pressure is $\sim 1$ mbar. The steady state regime at $450 \mathrm{~K}$ was first achieved prior to the following stepwise increasing the temperature. The $\mathrm{CO}$ and $\mathrm{CO}_{2}$ traces were offset for clarity.

Therefore, the XPS results show that $\mathrm{O}_{2}$ treatment of the monolayer $\mathrm{MnO}$ film at mbar pressure leads to a new $\mathrm{O}$ species which is characterized by about $1.8 \mathrm{eV}$ higher binding energy of the 01 s core level as compared to the oxygen atoms initially present in the film. The additional $\mathrm{O}$ species could tentatively be assigned to the topmost $\mathrm{O}$ atoms in the O-Mn-O trilayer structure. The presence of these $\mathrm{O}$ species correlates well with enhanced reactivity of the film in low temperature $\mathrm{CO}$ oxidation.

\section{Conclusions}

The principal structure of monolayer $\mathrm{MnO}$ films grown on $\mathrm{Pt}(111)$ was studied by LEED, HREELS, AES, XPS and TPD at various chemical potential of oxygen (pressure, temperature). It is found that the monolayer $\mathrm{MnO}-(19 \times 1)$ film prepared under UHV conditions readily transforms into "O-rich" films, which can be assigned, at least partially, to a O-Mn-O trilayer structure. The resulted films are fairly stable in a wide range of oxygen chemical potentials, although may show different degree of long-range ordering.

The monolayer $\mathrm{MnO}$ films were examined in the low temperature $\mathrm{CO}$ oxidation reaction at near atmospheric pressures. Reactivity studies revealed that the reaction rate over $\mathrm{MnO}$ films is higher than the $\mathrm{Pt}(111)$ support itself, but lower than FeO films studied 
under the same conditions. For stable catalytic performance MnO films required highly oxidizing reaction conditions $\left(\mathrm{CO}: \mathrm{O}_{2}<1: 10\right)$ to prevent film dewetting which causes irreversible catalyst deactivation.

The results show that the reactivity of $\mathrm{MnO}_{x}$ ultrathin films is governed by a weakly bonded oxygen species. Comparison with other ( $\mathrm{FeO}(111)$ and $\mathrm{ZnO}(111))$ films grown on the same Pt(111) shows, that desorption temperature of weakly bonded oxygen species can be used as a benchmark for activity in this reaction.

\section{Acknowledgements}

The Swedish part of the work was supported by the Swedish Research Council (VR) and the Göran Gustafsson Foundation. Prof. J. Schnadt, Dr. J. Knudsen and the MAX-lab staff are gratefully acknowledged for their support. The FHI team acknowledges the support from the COST Action CM1104 "Reducible oxide chemistry, structure and functions". WW, SS, and SP gratefully acknowledge financial support by the Deutsche Forschungsgemeinschaft through SFB 762 „Functionality of Oxidic Interfaces“. Finally, we thank Prof. L. Spiccia for fruitful discussions.

\section{References}

1. Freund, H.-J. and G. Pacchioni, Oxide ultra-thin films on metals: new materials for the design of supported metal catalysts. Chemical Society Reviews, 2008. 37(10): p. 2224-2242.

2. Giordano, L. and G. Pacchioni, Oxide Films at the Nanoscale: New Structures, New Functions, and New Materials. Accounts of Chemical Research, 2011. 44(11): p. 1244-1252.

3. Shaikhutdinov, S. and H.-J. Freund, Ultrathin Oxide Films on Metal Supports: StructureReactivity Relations. Annual Review of Physical Chemistry, 2012. 63(1): p. 619-633.

4. $\quad$ Ackermann, M.D., et al., Structure and Reactivity of Surface Oxides on Pt(110) during Catalytic CO Oxidation. Physical Review Letters, 2005. 95(25): p. 255505.

5. Gustafson, J., et al., Sensitivity of catalysis to surface structure: The example of CO oxidation on Rh under realistic conditions. Physical Review B, 2008. 78(4): p. 045423.

6. Lundgren, E., et al., Surface oxides on close-packed surfaces of late transition metals. Journal of Physics: Condensed Matter, 2006. 18(30): p. R481.

7. Sun, Y.N., et al., Monolayer iron oxide film on platinum promotes low temperature CO oxidation. Journal of Catalysis, 2009. 266(2): p. 359-368.

8. Ultrathin MgO Films. Journal of the American Chemical Society, 2009. 131(46): p. 1663616637. 
9. He, Y.B., et al., Oxidation of Ir(111): From O-Ir-O Trilayer to Bulk Oxide Formation. The Journal of Physical Chemistry C, 2008. 112(31): p. 11946-11953.

10. Sun, Y.-N., et al., The Interplay between Structure and CO Oxidation Catalysis on MetalSupported Ultrathin Oxide Films. Angewandte Chemie-International Edition, 2010. 49(26): p. 4418-4421.

11. Rogal, J., K. Reuter, and M. Scheffler, CO oxidation on Pd(100) at technologically relevant pressure conditions: First-principles kinetic Monte Carlo study. Physical Review B, 2008. 77(15): p. 155410.

12. Gustafson, J., et al., Self-Limited Growth of a Thin Oxide Layer on Rh(111). Physical Review Letters, 2004. 92(12): p. 126102.

13. Flege, J.I., J. Hrbek, and P. Sutter, Structural imaging of surface oxidation and oxidation catalysis on Ru(0001). Physical Review B, 2008. 78(16): p. 165407.

14. Martynova, Y., et al., CO oxidation over ZnO films on Pt(1\&\#xa0;1\&\#xa0;1) at nearatmospheric pressures. Journal of Catalysis, 2013. 301(0): p. 227-232.

15. Hagendorf, C., et al., Growth, atomic structure, and vibrational properties of $\mathrm{MnO}$ ultrathin films on Pt(111). Physical Review B, 2008. 77(7): p. 075406.

16. Sachert, S., et al., Thickness dependent vibrational and electronic properties of $\mathrm{MnO}(100)$ thin films grown on Pt(111). Physical Review B, 2010. 81(19): p. 195424.

17. Rizzi, G.A., et al., An X-ray photoelectron diffraction structural characterization of an epitaxial MnO ultrathin film on Pt(1\&\#xa0;1\&\#xa0;1). Surface Science, 2001. 482-485, Part 2(0): p. 1474-1480.

18. Müller, F., et al., Epitaxial growth of MnO/Ag(0\&\#xa0;0\&\#xa0;1) films. Surface Science, 2002. 520(3): p. 158-172.

19. Li, F., et al., Two-dimensional manganese oxide nanolayers on Pd(100): the surface phase diagram. Journal of Physics: Condensed Matter, 2009. 21(13): p. 134008.

20. Nishimura, H., et al. Surface structure of $\mathrm{MnO} / \mathrm{Rh}(100)$ studied by scanning tunneling microscopy and low-energy electron diffraction. 2000. Seattle, Washington (USA): AVS.

21. Zhang, L., et al., Growth and vibrational properties of MnOx thin films on Rh(111). Surface Science, 2012. 606(19-20): p. 1507-1511.

22. Schnadt, J., et al., The new ambient-pressure $X$-ray photoelectron spectroscopy instrument at MAX-lab. Journal of Synchrotron Radiation, 2012. 19(5): p. 701-704.

23. Feulner, P. and D. Menzel, Simple ways to improve "flash desorption" measurements from single crystal surfaces. Journal of Vacuum Science and Technology, 1980. 17(2): p. 662-663.

24. Kostov, K.L., et al., Surface-phonon dispersion of a NiO(100) thin film. Physical Review B, 2013. 87(23): p. 235416.

25. Franchini, C., et al., Density functional study of the polar MnO(111) surface. Physical Review B, 2006. 73(15): p. 155402.

26. Martynova, Y., et al., Low Temperature CO Oxidation on Ruthenium Oxide Thin Films at NearAtmospheric Pressures. Catalysis Letters, 2012. 142(6): p. 657-663.

27. Bagus, P.S. and E.S. Ilton, Effects of covalency on the $p$-shell photoemission of transition metals: MnO. Physical Review B, 2006. 73(15): p. 155110. 